\title{
DERMATOFITOSES NO MEIO URBANO E A COEXISTÊNCIA DO HOMEM COM CÃES E GATOS
}

\author{
Adriana de Queiroz Pinheiro, José Luciano Bezerra Moreira \\ e José Júlio Costa Sidrim
}

\begin{abstract}
Foram submetidos a exame clinico laboratorial de dermatofitose e inqueridos sobre o possível contato com cães e gatos 158 pacientes residentes na área urbana de Fortaleza, que apresentavam lesôes suspeitas de dermatofitose. Esta busca associada aos dados obtidos em questionário permitiram identificar a freqüência de surtos domiciliares. Dentre os 83 dermatófitos isolados de infecções humanas, predominaram as espécies antropofílicas sobre as zoofílicas, tendo sido observado uma confluência de diagnóstico bumano e animal em 100\% dos casos de dermatofitoses zoofílicas humanas, onde foram identificadas as mesmas espécies no bomem e nos animais contactantes: Microsporum canis e Trichophyton mentagrophytes. Já os pacientes portadores de dermatófitos antropofílicos variaram quanto ao contato com animais domésticos, não tendo sido isolado estes fungos de nenhum animal contactante. Diante da baixa freqüência de dermatofitoses zoofílicas, considerou-se que o convivio do homem com cães e gatos domésticos foi pouco representativo como fator condicionante da ocorrência de dermatofitoses no meio urbano.
\end{abstract}

Palauras-chaves: Dermatofitoses. Epidemiologia. Cães. Gatos. Urbano.

Apesar do grande progresso da ciência e da tecnologia para a proteção do homem contra as enfermidades infecciosas e parasitárias, e dos esforços das entidades governamentais para controlá-las ou erradicá-las, tais doenças continuam figurando nas estatísticas de saúde dos países tropicais com elevadas taxas de morbidade, constituindo a causa de grande parte das disfunções orgânicas registradas na maioria desses países 144.

Ademais, muitas dessas infecções têm uma elevada prevalência em diversas espécies de animais, particularmente em cães e gatos. Estes últimos convivem com o homem e com ele dividem o mesmo "nicho urbano"5 33 . Essa convivência tem motivado diversos pesquisadores a, nas últimas décadas, desenvolverem investigações no sentido de conhecer a extensão da ligação entre o homem urbano e os animais de companhia, os quais, em última

Departamento de Patologia e Medicina legal da Faculdade de Medicina da Universidade Federal do Ceará, Fortaleza, CE Órgão financiador: CAPES

Endereço para correspondência: Dr. José Júlio Costa Sidrim. Laboratório de Micologia Médica/Departamento de Patologia e Medicina Legal. R. Monsenhor Furtado $s / n^{\circ}$, Rodolfo Teófilo, Caixa Postal 3163, 60441-750 Fortaleza, CE, Brasil. Tel: (085) 243-9301; Fax: (085) 295-1736.

E-mail:JBF96@sec.secrel.com.br

Recebido para publicação em 21/10/96. análise, são considerados reservatórios potenciais de algumas patologias humanas7 89222631 .

As dermatofitoses são um exemplo de enfermidade infecciosa com elevada prevalência na América Latina e que atinge tanto o homem como os animais domésticos 244271 . No que tange à saúde humana, segundo Murray e cols36, os relatos fragmentados e dados epidemiológicos indicam que estas micoses estão entre as zoonoses mais comuns do mundo, sendo consideradas o terceiro distúrbio de pele mais comum em crianças menores de 12 anos e o segundo da população adulta. Se bem sejam escassos os dados epidemiológicos referentes ao alcance da doença entre os animais, a literatura relata a ocorrência bastante comum da enfermidade entre cães e gatos no meio urbano4 192435 .

Levando em conta a elevada freqüência das dermatofitoses em centros urbanos, muitos autores destacaram o papel disseminador desempenhado pelos pequenos mamíferos domésticos, sobretudo cães e gatos, atuando como potenciais reservatórios de fungos patogênicos para o homem3 467.131516182830323739 .

O presente trabalho, diante da relevância de que se revestem os desenvolvimentos a respeito da epidemiologia das dermatofitoses para os campos da saúde humana e animal, procurou investigar essas doenças, analisandoas no contexto ecológico e epidemiológico do 
Pinheiro AQ, Moreira JLB, Sidrim JJC. Dermatofitoses no meio urbano e a coexistência do homem com cães e gatos. Revista da Sociedade Brasileira de Medicina Tropical 30:287-294, jul-ago, 1997.

meio urbano. Para tanto, foram considerados os seguintes aspectos: a etiologia das dermatofitoses na população de Fortaleza, a freqüência de dermatófitos zoofílicos na ocorrência da doença no homem, a correlação entre o convívio do homem com cães e/ou gatos e a ocorrência de surtos familiares da doença.

\section{MATERIAL E MÉTODOS}

Foram incluídos no presente estudo 158 pacientes residentes da área urbana de Fortaleza e atendidos para exame clínico no ambulatório de Dermatologia e Pediatria do Hospital Universitário Walter Cantídio, que apresentavam lesões suspeitas de dermatofitose, os quais foram submetidos, à coleta de amostras dermatológicas e inqueridos sobre o convívio com cães e/ou gatos domésticos.

Conforme resultados obtidos do exame micológico, incluindo pesquisa direta, cultura e identificação dos dermatófitos, o estudo foi divido em dois grupos: um grupo com características clínicas de dermatofitose mas com pesquisa e/ou cultura negativa e um outro grupo com dermatofitose diagnosticada clinica laboratorialmente. Esses grupos foram subdividos através dos questionários em outros dois: um com contato domiciliar com cães ou gatos e outro não. A partir dos pacientes com dermatofitose foi realizada busca ativa de casos de dermatofitose animal e humana, onde foram coletadas espécimes clínicos dos contactantes humanos apresentando lesões dermatológicas suspeitas e dos animais com ou sem lesões dermatológicas. A busca ativa de casos de dermatofitose animal e humana associado aos dados obtidos no questionário permitiram detectar a freqüência de surtos domiciliares (microepidemias*).

A coleta do material clínico humano e animal seguiu a metodologia preconizada por Badillet 2 , onde nos animais com lesões dermatológicas perceptíveis, o procedimento de coleta foi o mesmo executado para as lesões do couro cabeludo dos pacientes humanos, ou seja raspado do couro cabeludo com o lado rombóide de lâmina de bisturí e retirada dos pelos com pinça. A coleta de

\footnotetext{
* Microepidemias: surtos epidêmicos em um contexto social restrito, onde são registrados mais de um caso da doença em questão10.
}

material dos animais aparentemente normais foi executada conforme a metodologia utilizada por Moreira e cols35. Todo material clínico coletado foi acondicionado em placa de Petri estéril à temperatura ambiente para processamento laboratorial no prazo máximo de 24 horas.

O exame microscópico direto de todas as amostras clínicas coletadas consistiu na suspensão de alíquotas do material coletado em uma gota de hidróxido de potássio a 40\% em uma preparação lâmina-lamínula. Alíquotas do material coletado foram semeadas primariamente em meios de Sabouraud sem antibiótico, Sabouraud com cloranfenicol e Mycosel. A incubação foi feita em temperatura ambiente $\left(25-28^{\circ} \mathrm{C}\right)$ em um prazo máximo de 20 dias, com observação diária. As espécies de dermatófitos foram identificadas segundo Badillet $^{2}$ e Lacaz ${ }^{24}$, tomando-se como base a combinação de características macroscópicas e microscópicas das colônias de dermatófitos em crescimento, bem como de suas exigências nutricionais. A correlação entre a ocorrência de dermatofitose e o contato com animais foi realizada através do teste de Yule25.

\section{RESULTADOS}

O estudo biológico das amostras clínicas coletadas de 158 pacientes com lesões dermatológicas, permitiu diagnosticar dermatofitose em 83 pacientes, o que corresponde a $52,5 \%$ do total.

Dos 83 pacientes com dermatofitose inqueridos sobre o convívio doméstico com cães ou gatos, 35 (29\%) referiram contato com estes animais, já dos 75 pacientes que não apresentavam dermatofitose, 33 (42,3\%) referiam contato com cães e/ou gatos. Através da análise setatística segundo o critério de Yule, verificou-se independência entre as duas variáveis: $\mathrm{Y}=-0,08$ entre a freqüência de dermatofitoses no meio urbano e o convívio do homem com cães e gatos (Figura 1).

Das 83 cepas de dermatófitos isoladas de infecções humanas, foram identificadas cinco espécies, cujas freqüências, em ordem decrescente, foram: Trichophyton rubrum, 45,7\% (38 casos); Trichophyton tonsurans, 32,5\% (27 casos); Trichophyton mentagrophytes var. lanosa, 6\% (5 casos); Trichophyton. mentagrophytes var. granular, 6\% (5 casos); Microsporum canis, 8,5\% (7 casos) e Microsporum gypseum, 1,2 \% (1 caso). 
Pinheiro AQ, Moreira JLB, Sidrim JJC. Dermatofitoses no meio urbano e a coexistência do homem com cães e gatos. Revista da Sociedade Brasileira de Medicina Tropical 30:287-294, jul-ago, 1997.

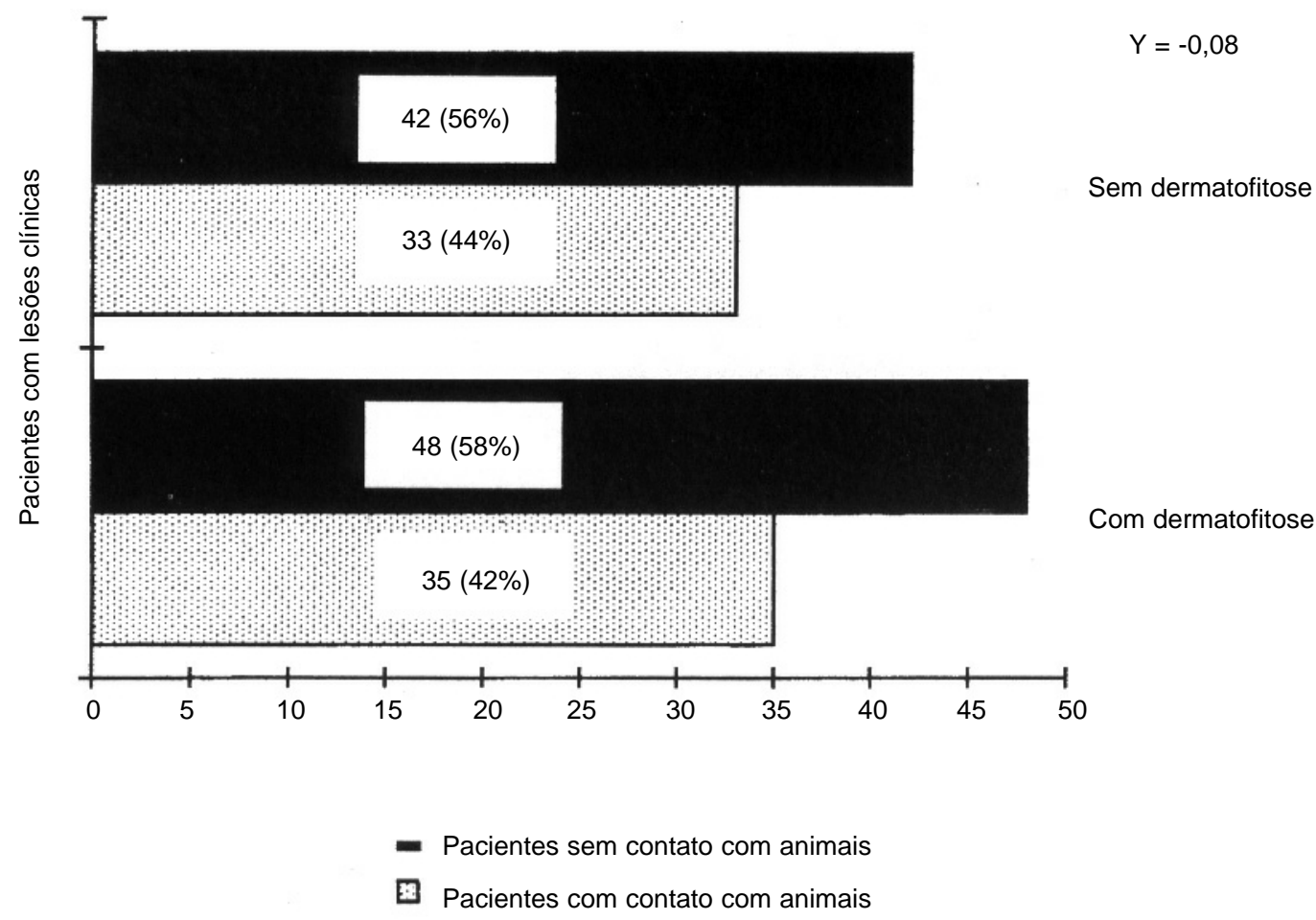

Figura 1 - Relação entre a ocorrência de mermatofitose e o contato com cães e gatos.

Na Figura 1, dos 68 pacientes com lesões clínicas que referiram contato com cães e gatos domésticos, foi isolado dermatófito em 42\%. Já dos 90 pacientes com lesão clinica e que não referiram contato com estes animais, foi isolado dermatófito em 58\% desses pacientes. Analisados os dados pelo teste de YULE não existe relação entre o contato com animais e a presença de dermatofitose.

Foi colhido material clínico de 35 animais contactantes de pacientes com lesão clínica/laboratorial de dermatofitose, sendo feita a correlação de apenas um animal por família para cada paciente-chave*. Dos animais investigados, $12(34,2 \%)$ mostraram-se positivos para dermatofitose, onde foram identificados duas espécies na seguinte ordem de freqüência: Microsporum canis, 58,3\% (7 casos)

\footnotetext{
* Paciente-chave: Paciente humano no qual foi realizado o isolamento primário do fungo, sendo o mesmo, o elo da cadeia epidemiológica.
}

e Trichopbyton mentagropbytes, 41,6\% (5 casos).

Observou-se nos pacientes-chaves com dermatofitose tipo zoofílica e contactantes de cães ou gatos uma elevada correlação da dermatofitose e este contato, isto é, de todos os pacientes-chaves que referiram contato com animais domésticos (12 pacientes) foi isolado o mesmo dermatófito humano do animal contactante. Já os pacientes-chaves portadores de cepas antropofílicas com contato com animais domésticos não foi observado isolamento de fungo deste grupo em nenhum dos animais pertencente ao estudo. A correlação entre as espécies de dermatofitos humanos isolados e o contato com animais podem ser observados na Figura 2 .

Na Figura 2, observa-se a elevada correlação entre as dermatofitoses zoofílicas por $T$. mentagrophytes var. granular e $M$. canis e o contato com cães e gatos.

A busca ativa permitiu a detecção de microepidemias familiares onde os dermatófitos 
Pinheiro AQ, Moreira JLB, Sidrim JJC. Dermatofitoses no meio urbano e a coexistência do homem com cães e gatos. Revista da Sociedade Brasileira de Medicina Tropical 30:287-294, jul-ago, 1997.

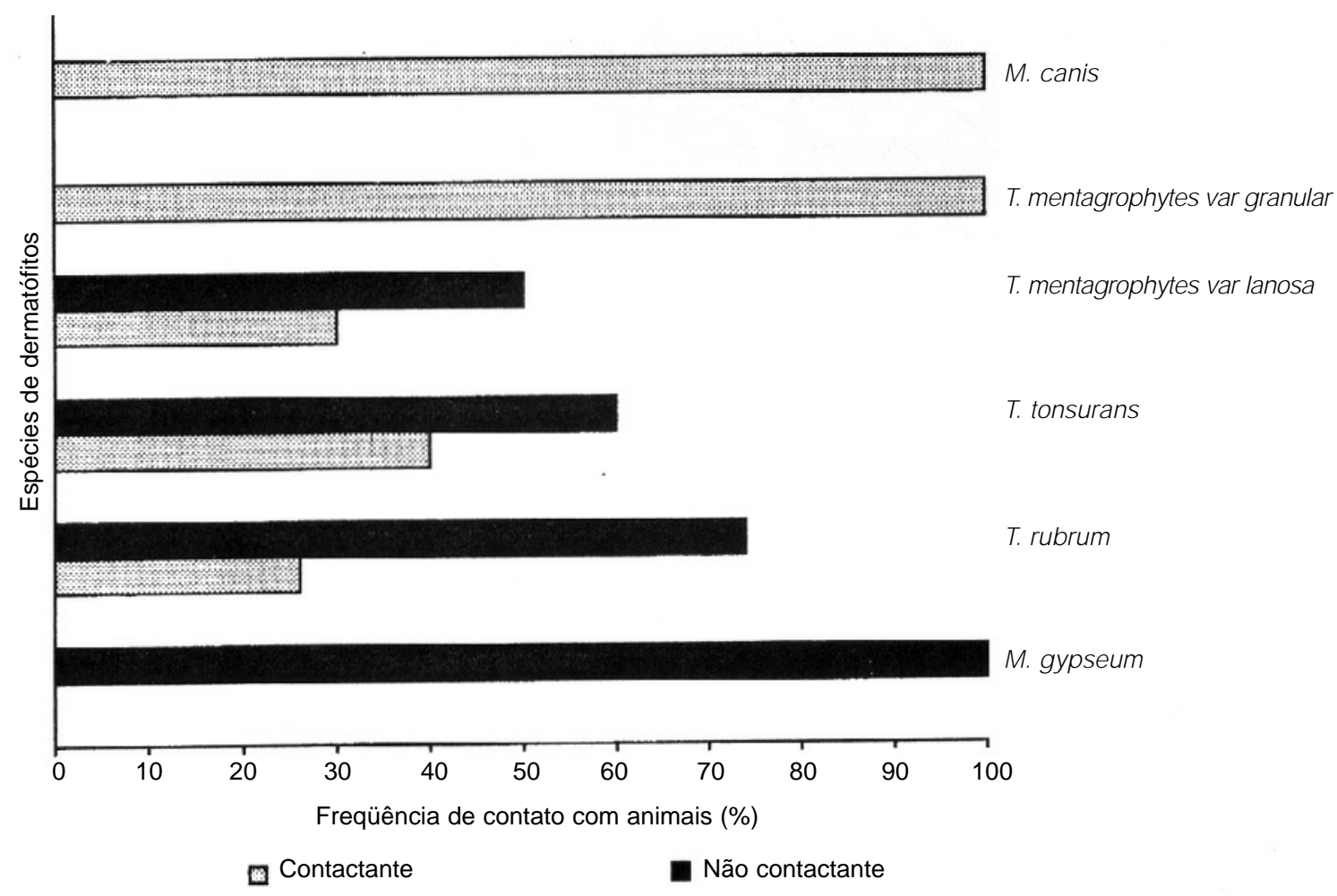

Figura 2 - Relação entre as espécies isoladas e o contato dos pacientes com cães e gatos.

em questão, isto é, a mesma espécie do dermatófito isolado do paciente-chave era detectado em pelo menos mais um membro da família. Foram observadas 10 microepidemias familiares, das quais 8 eram contactantes de cães e gatos e duas não relatavam este contato. Das 8 microepidemias onde evidenciou-se o contato com animais domésticos apenas 3 eram por dermatófitos zoofílicos, sendo o restante por dermatófitos antropofílicos; nas outras 2 microepidemias, onde o contato com animais domésticos não foi evidenciado os dermatófitos em questão eram do grupo antropofílico. O número total de dermatófitos isolados, excluindo o paciente-chave de cada família, foi de 23 cepas de dermatófitos antropofílicos contra 6 de dermatófitos zoofílicos. Os dados das microepidemias familiares encontram-se na Tabela 1 e Figura 3.

Tabela 1 - Microepidemias familiares.

\begin{tabular}{|c|c|c|c|c|c|c|c|c|c|c|c|}
\hline Paciente-chave & JFS & LPB & MRA & $\mathrm{CMO}$ & QH & RS & HTS & FLA & $\mathrm{AQP}$ & PBC & Total \\
\hline \multirow[t]{2}{*}{ Dermatófito isolado } & $T$. & $T$. & $T$. & $T$. & $T$. & $T$. & $T$. & $M$. & $M$. & $M$. & \\
\hline & rubrum & tonsurans & tonsurans & tonsurans & tonsurans & tonsurans & tonsurans & canis & canis & canis & \\
\hline \multirow[t]{2}{*}{ Famílias } & $\mathrm{A}$ & $\mathrm{B}$ & $\mathrm{C}$ & $\mathrm{D}$ & $\mathrm{E}$ & $\mathrm{F}$ & $\mathrm{G}$ & $\mathrm{H}$ & I & $\mathrm{J}$ & 10 famílias \\
\hline & \multicolumn{10}{|c|}{ Freqüência de dermatófitos isolados de familiares dos pacientes-chaves } & \\
\hline № de familiares & 8 & 6 & 6 & 6 & 9 & 6 & 8 & 6 & 5 & 5 & 65 \\
\hline T. tonsurans & - & 3 & 4 & 4 & 5 & 2 & 4 & 1 & - & - & 23 \\
\hline T. rubrum & 2 & - & - & - & - & - & - & - & - & - & 2 \\
\hline T. mentagrophytes & - & - & - & - & - & - & - & - & - & - & 0 \\
\hline M. canis & - & - & - & - & - & - & - & 1 & 2 & 3 & 6 \\
\hline M. gypseum & - & - & - & - & - & - & - & - & - & - & 0 \\
\hline Negativos & 6 & 3 & 2 & 2 & 4 & 4 & 4 & 4 & 3 & 2 & 3 \\
\hline
\end{tabular}




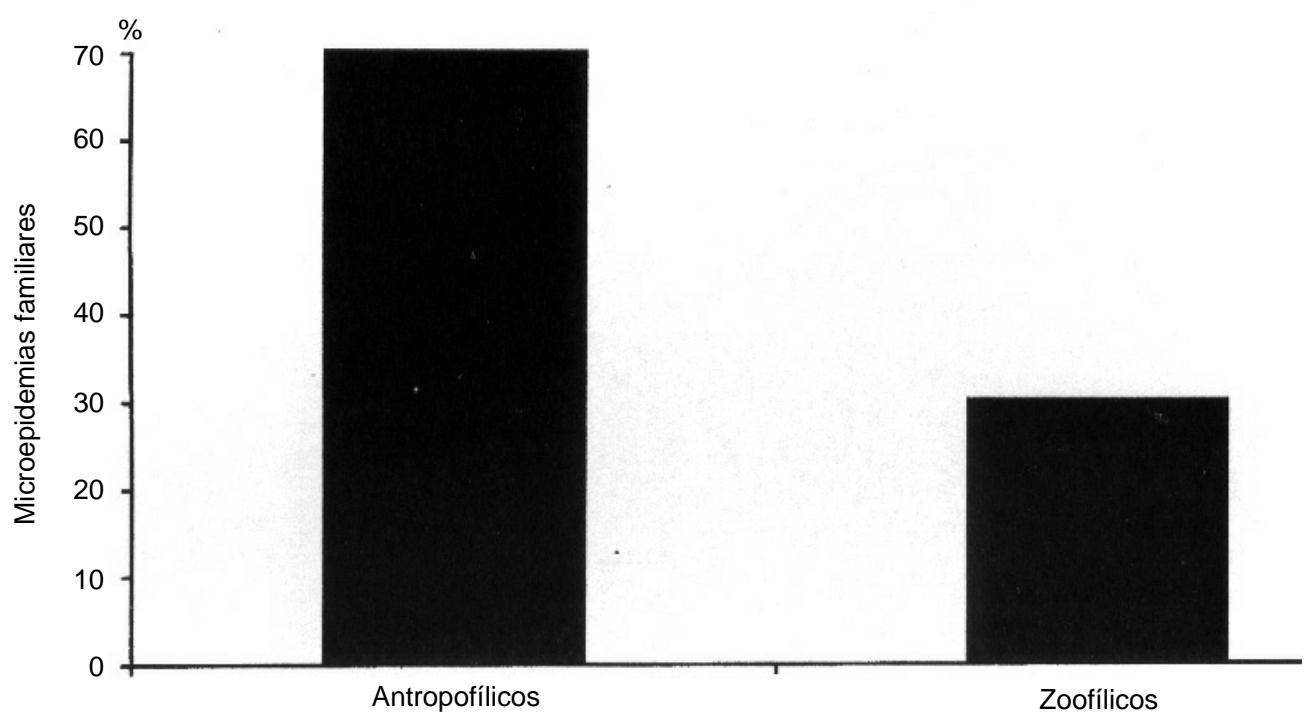

Ecologia dos dermatófitos

Figura 3 - Freqüência das microepidemias familiares quanto à ecologia dos dermatófitos.

Na Figura 3, observa-se a elevada freqüência de microepidemias familiares por dermatófitos do grupo antropofílico.

\section{DISCUSSÃO}

Alguns autores relataram a incidência das dermatofitoses em centros urbanos de diversas regiões do Brasil11 121427 34. Nossa casuística demonstrou a existência do problema em Fortaleza. Acredita-se, contudo, que não existe uma idéia exata sobre a extensão da doença no nosso meio, uma vez que, segundo afirmou Proença 40 , na prática médica a grande maioria dos diagnósticos das micoses cutâneas é firmado única e exclusivamente com base na observação clínica, de modo que os procedimentos laboratoriais não são habitualmente solicitados pelos médicos que estão assistindo aos pacientes. Considerando o exposto, admite-se que as dermatofitoses podem ter freqüência muito maior do que assinalam as pesquisas.

Nessa perspectiva, a literatura aponta diversos fatores condicionantes da ocorrência de dermatofitoses no meio urbano14 18243045. Muitos profissionais da área de saúde pública e dermatologia ressaltam o contato do homem com cães e gatos domésticos como um desses fatores predisponentes, e não apreciam essa ligação, por considerarem os animais potenciais reservatórios de fungos patogênicos, aconselhando seus pacientes portadores de enfermidades dermatológicas a se desfazerem de seus animais de estimação, ainda que sem a confirmação do diagnóstico etiológico da doença22 43 .

Em contrapartida, nas últimas décadas, pesquisas foram desenvolvidas no sentido de demonstrar que existe uma tendência crescente do homem urbano de conviver com animais domésticos, sobretudo cães e gatos, e a intensidade dessa ligação pôde ser comprovada através do fato de que a maior parte dos pacientes com lesões dermatológicas não cumprem as recomendações dos dermatologistas para se desvincularem dos seus animais de estimação8 263143.

A presente investigação registrou que 43,3\% de todos os pacientes inqueridos, fossem estes portadores de dermatofitoses ou não, eram proprietários de cães e gatos de estimação. Portanto, considera-se que a dissolução do vínculo do homem urbano com seus animais 
Pinheiro AQ, Moreira JLB, Sidrim JJC. Dermatofitoses no meio urbano e a coexistência do homem com cães e gatos. Revista da Sociedade Brasileira de Medicina Tropical 30:287-294, jul-ago, 1997.

de estimação frente à ocorrência de possíveis zoonoses, representa, antes de uma recomendação médica de ordem profilática, um problema que requer reflexão interdisciplinar, envolvendo principalmente o médico e o veterinário, no sentido de preservar tanto a saúde humana como a saúde animal de doenças como as dermatofitoses, sem causar prejuízos para o equilíbrio social e ecológico do meio urbano.

Os dados obtidos nesse estudo apontaram para uma freqüência maior das espécies antropofílicas sobre as zoofílicas na etiologia de dermatofitoses humanas no meio urbano. Tais resultados contrastaram com achados de pesquisas realizadas em regiões rurais, onde se caracteriza o contato direto do homem com os animais domésticos de diferentes espécies. Ali, foi relatada com maior freqüência a ocorrência de dermatofitoses zoofúlicas29. Este fato demonstra que a predominância das dermatofitoses antropofílicas representa o perfil provável da flora dermatofítica urbana.

Em raras publicações foi registrada a ocorrência de dermatofitose por espécies antropofílicas em animais domésticos ${ }^{17} 20$. Isso não foi verificado em nenhum dos animais contactantes aos quais se refere a pesquisa, permitindo inferir-se a inexistência de relação entre a infecção humana por dermatófitos antropofílicos e a posse de animais de estimação. Esse fato coaduna-se com a literatura a respeito13 1618 , toda voltada no sentido de considerar incomum o fenômeno dos dermatófitos descenderem na cadeia ecológica, ou seja, é possível a infeccão humana por dermatófitos zoofílicos ou geofílicos, entretanto é rara a infecção animal por dermatófitos antropofílicos, os quais dificilmente regridem na cadeia ecológica.

Dermatófito antropofílico por exelência, o Trichophyton rubrum foi a espécie predominante do total de dermatófitos isolados. Apesar disso, esta espécie foi o agente de apenas $1 \%$ das microepidemias familiares de dermatofitose. Nesse sentido, a literatura explica que as dermatofitoses por esta espécie não são doenças contagiosas e que a infecção pode estar associada a fatores imunológicos individuais, uma vez que estes fungos antropofílicos, parasitas obrigatórios, estejam disseminados em ambientes ricos em substratos queratinosos humanos, onde existem aglomerados populacionais, e dessa forma, todos nós, diariamente, nos infectamos com esporos desses fungos, embora nem todos manifestem clinicamente a doença 42 .

Já o Trichophyton tonsurans destacou-se como o segundo maior causador de dermatofitose em pacientes humanos, entretanto, ao contrário do que ocorreu com o T. rubrum, verificou-se alta freqüência de $T$. tonsurans nas microepidemias familiares.A exemplo desses resultados, outros autores 38 referiram esta espécie como causadora de graves surtos epidêmicos de tinhas de couro cabeludo em colégios. Em outros centros urbanos este dermatófito antropofílico foi introduzido a partir de correntes migratórias e, uma vez instalado, tornou-se a espécie dominante 41 . É possível que fato semelhante tenha ocorrido no nosso meio, onde o aglomerado populacional urbano possa ter favorecido o domínio das espécies antropofílicas sobre as zoofílicas.

Considerando o exposto, é possível admitir que a ocorrência de dermatofitose por espécies antropofílicas está, direta ou indiretamente, associada a diversos fatores, entre os quais não se inclui o contato com cães e gatos domésticos. Quanto às infecções humanas por dermatófitos zoofílicos, estas, apesar de esporádicas, estão diretamente associadas a animais infectados. Os resultados demonstraram a presença no mesmo domicílio de cães e pessoas infectadas por Microsporum canis ou Trichophyton mentagrophytes var. granular. Entretanto, este fato não inviabiliza o convívio do homem com cães e gatos domésticos, uma vez que as dermatofitoses zoofílicas no meio urbano apresentaram baixa freqüência e $\mathrm{O}$ convívio do homem com animais domésticos teve pequena representação nas microepidemias familiares por dermatófitos antropofílicos.

Entende-se, portanto, que os dados obtidos ao longo do trabalho tenham contribuído para o estudo epidemiológico das dermatofitoses e revelado a importância do diagnóstico laboratorial para a conduta profilática dos dermatologistas frente à ocorrência de dermatofitoses humanas. Uma vez que tendo o conhecimento da espécie de dermatófito agente da infecção, esses profissionais não comprometerão em vão o vínculo do paciente com seus animais de estimação. Da mesma forma, entendido que o convívio entre homens e animais domésticos não é necessariamente insalubre, cumpre ao veterinário a solicitação do diagnóstico laboratorial para as dermatofitoses 
Pinheiro AQ, Moreira JLB, Sidrim JJC. Dermatofitoses no meio urbano e a coexistência do homem com cães e gatos. Revista da Sociedade Brasileira de Medicina Tropical 30:287-294, jul-ago, 1997.

animais, restabelecendo adequadamente a saúde animal e protegendo indiretamente a saúde humana, tornando perfeitamente viável a interação salutar entre o homem e os animais domésticos no meio urbano.

\section{SUMMARY}

There have been submitted to clinical exam in laboratory of dermatofitosis and inquired about possible contact with domestic animals (dogs and cats) 158 patients living in the urban area of Fortaleza, that showed lesions suspected of dermatofitosis. This search associated to the obtained data in questionnaires permitted us to identify the frquency of domicile outbreaks. Within the 83 people with dermatosis isolated of human infections, prevailed the anthopophylical species over the zoophylical ones, and that it was observed a confluence of human and animal diagnosis in $100 \%$ of the human dermatophytosis zoophylical cases, where the same species were identified in men and contacting animals: $\mathrm{M}$. canis and $\mathrm{T}$. mentagrophytes. As the patients carrying antropophylical dermatophytosis varied as to the contact with animals, not having been these fungus isolated from none of the contacting animals. Before the low frequency of zoophylical dermatophytosis, it was considered that the intimacy of men with domestic dogs and cats represented was little as a conditional factor of occurrence of dermatophytosis in the urban environment.

Key-words: Dermatophytosis. Epidemiology. Dogs. Cats. Urban

\section{REFERÊNCIAS BIBLIOGRÁFICAS}

1. Acha PN, Szyfres, B Zoonosis y enfermidades transmissibiles comunes al hombre y a los animales. Oficina Sanitaria Panamericana. Washington, 1977.

2. Badillet G. Les Dermatophytes. atlas clínique et biologique. Ed. Var. Paris, 1979

3. Badillet G, Population parisienne et dermatophytes transmis par les animaux. Bulletin Societé Française Mycologie Medicale 6:109-114, 1977.

4. Badillet G, Laissus R, Pietrine P, Vivas, M. Flore mycologique potentiellement pathógene pour l'homme recuillie sur le pelage de chiens abandonnés. Bulletin Societé Française Mycologie Medicale 1:29-32, 1972.

5. Beck A. The public health implications of urban dogs.The American Journal Public Health 65:1315, 1975.
6. Blank F. Dermatophytes of animal origen transmissible to man. The American Journal of the Medical Sciences 229:302-316, 1955.

7. Brown L. Affection for people as a function of affection for dog. Psychological Reports 31:957, 1990.

8. Cameron P. Psycological correlates of pet ownership. Psychological Reports 30:286, 1972.

9. Condoret A. Pour une biologie du comportement de l'enfantsa relation a l'animal familier. Bulletin de La' Academie Veterinaire de France 50:481, 1987.

10. Cortes JA. Epidemiologia:conceitos e princípios fundamentais. Livraria Varela. São Paulo, 1993.

11. Costa FC, Wanke B. Martins CSM. Micoses superficiais e cutâneas: estudo comparativo entre duas populações: Rio de Janeiro (RJ) e Aracaju (SE). Anais Brasileiros de Dermatologia 66:120121, 1991.

12. Cucé C. Flora dermatofítica em São Paulo (19641974). Anais Brasileiros de Dermatologia 50:141146, 1975.

13. De Vroey $\mathrm{CH}$. Ecological and epidemiological aspects in dermatophytozoonoses. Bakteriologie Mikrobiologie und Hygiene 257:234-239, 1984.

14. Diaz MC, Salamanca L, Piontelli E. Dermatofitosis: un problema del pasado, un desafío del presente. Adelantos en Microbiologia e Enfermidades Infecciosas 3:212-273, 1984.

15. English MP. The epidemiology of animal ringworm in man. The British Journal Dermatolgy 86:78-87, 1972.

16. Georg LK. The role of animals as vectores of human fungus diseases. Transactions of the New York Academie Sciences 2:639- 647, 1956.

17. Gip L, Martin B. Isolation of Trichophyton terrestre, Trichophyton mentagrophytes var. asteroides and Trichophyton rubrum from dogs. Acta Dermato Venereologica 44:248-250, 1964.

18. Gonzalez Cabo JF. Epidemiologia de las dermatofitosis animales. Bolletin Micologico 5:29-42, 1990 .

19. Houin R, Fichoux Y, Puel F, Campina- Rouget Y. Etude mycologic de petits mammiferes de l'Est de la France. Bulletin Societé Française Mycologie Médicale 11:161-164, 1973.

20. Hushida T, Watanabe S. Canine ringworm caused by Trichophyton rubrum: Probable transmission from man to animal. Sabouraudia 13:30-32, 1975. 
21. Kaplan W, Ajello L. Therapy of spontaneous ringworm in cats with orally administered griseofulvin.Archives of Dermatological 81:714 723, 1960.

22. Katcher A, Friedman E. Potential health value of pet owership. Practices Veteterinay 2:117, 1980.

23. Lacaz CS, Porto E, Martins JEC. Morfologia e biologia dos fungos de interesse médico. In: Micologia Médica, Sarvier, São Paulo, cap. 2, p. 3184, 1991.

24. Lacaz CS, Porto E., Martins JEC. Fungos, Actinomicetos, algas e meio ambiente. Epidemiologia das micoses. In: Micologia Médica, Sarvier, São Paulo, cap. 5, p. 94-106, 1991.

25. Lauret R. Estatística de saúde. EDUSP. São Paulo. 1985.

26. Leigh D. The psychology of the pet ower. Journal Small Animals Practices 7:517, 1966.

27. Leite RMS, Fogaça SA, Santos MG, Maia HCA. Dermatofitose em Brasília. HFA Publicações Técnicas Científicas 5:.29-42, 1990.

28. Londero AT, Fischman O, Ramos CD. Importância do gato na transmissão do Microsporum canis no Rio Grande do Sul. Revista do Instituto de Medicina Tropical 3:81-84, 1961.

29. Londero AT, Ramos CD. Agentes de dermatofitose humana no interior do Rio Grande do Sul. Anais Brasileiros de Dermatologia 64:161-164, 1989.

30. López Martinez R. Investigación de algunas fuentes de infección en las dermatofitosis. Estudio de suelo, animales y hombre. Gaceta Médica de México 122:167-172, 1986.

31. MacDonald A. Review. Children and companion animals. Children:Care Health and Development 5:347, 1989.

32. Mantovani A. The role of animals in the epidemiology of the mycoses. Mycopathologia 65:61-66, 1978.

33. Mantovani A, Batelli G, Zanetti R. Problems associated with the coexistence of man and animals in urban areas. Annali Dell'Instuto Superiori di Sanita 14:265-272, 1978.
34. Martine JP, Souza LCD, Costa HC. Dermatófitos isolados em pacientes do hospital "Lauro de Souza Lima"de Bauru. Salusvita 6:1-6, 1987.

35. Moreira YK. Fungos queratinofílicos patogênicos para o homem, nos pêlos de cães e gatos normais. Arquivos da Escola Veterinária Universidade Federal de Minas Gerais 22:141-144, 1970.

36. Murray PR, Drew WL, Korbay JGS. Superficial, Cutaneous, an Subcutaneous Mycoses. In: Microbiology Medical, Mosby Co,. St. Louis, Charpter 43, 1994.

37. Otcenasek M, Rosick B. Some ecological criteria of natural focality of mycotic zoonoses. Folia Parasitologica (Praha) 26:351-360, 1979.

38. Perret MP, Melo MGM., Oliveira JMPVC, Pereira RFB, Assis TL, Azulay RD. Inquérito epidemiológico das dermatoses na população escolar de 4 a 18 anos das Ilhas do Governador e do Fundo. Anais Brasileiros de Dermatologia 66:71-74, 1991

39. Philpot CM. Some aspects of the epidemiology of tinea. Mycopathologia 92:3-13, 1977.

40. Proença NG. Revisão. Dermatofitose na infância: aspectos clínicos e terapêuticos. Revista Paulista de Medicina 108:279-284, 1991.

41. Ramos CD, Rojas SF, Londero AT. Dermatofitoses por Trichophyton tonsurans observados no Rio Grande do Sul. Rev.Amrigs 25:236-238, 1981.

42. Rippon JW. Dermatophytosis and Dermatomycosis. In: Medical Mycology. W.B Saunders Company, Philadelphia, cap.8, p.169$275,1988$.

43. Speck R. Mental health problems involving the family, the pet, and veterinarian. Journal of American Veterinary Medical Association 145:2, 1984.

44. Veronesi R. Doenças infecciosas e parasitárias. $8^{\mathrm{a}}$ edição. Guanabara Koogan, Rio de Janeiro, 1993.

45. Wanke NCF, Monteiro PCF, Wanke B, Nogueira CM, Perez MA. Dermatofitoses no Rio de Janeiro: estudo dos fatores de risco em população adulta. Anais Brasileiros de Dermatologia 66:171-174, 1991. 